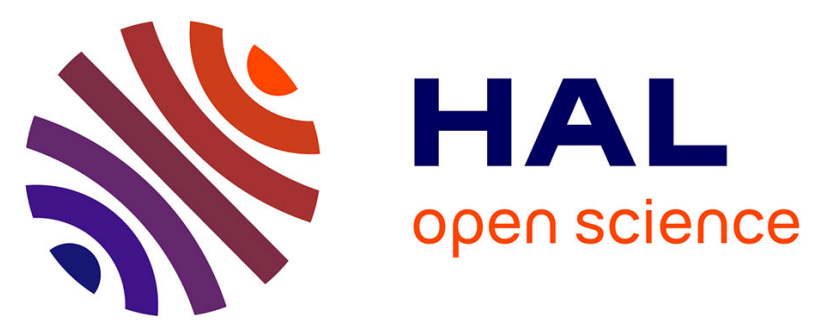

\title{
Patient-Centered Simulations to Assess the Usefulness of the 70-Gene Signature for Adjuvant Chemotherapy Administration in Early-Stage Breast Cancer
}

Emmanuel Caruana, Yohann Foucher, Philippe Tessier, Jean-Sébastien Frenel, Jean-Marc Classe, Etienne Dantan

\section{To cite this version:}

Emmanuel Caruana, Yohann Foucher, Philippe Tessier, Jean-Sébastien Frenel, Jean-Marc Classe, et al.. Patient-Centered Simulations to Assess the Usefulness of the 70-Gene Signature for Adjuvant Chemotherapy Administration in Early-Stage Breast Cancer. Breast Cancer Research and Treatment, 2019, 174 (2), pp.537-542. 10.1007/s10549-018-05107-6 . hal-03158776

\section{HAL Id: hal-03158776 \\ https://hal.science/hal-03158776}

Submitted on 21 Sep 2021

HAL is a multi-disciplinary open access archive for the deposit and dissemination of scientific research documents, whether they are published or not. The documents may come from teaching and research institutions in France or abroad, or from public or private research centers.
L'archive ouverte pluridisciplinaire HAL, est destinée au dépôt et à la diffusion de documents scientifiques de niveau recherche, publiés ou non, émanant des établissements d'enseignement et de recherche français ou étrangers, des laboratoires publics ou privés. 
Patient-centered simulations to assess the usefulness of the 70 -gene signature for adjuvant chemotherapy administration in early-stage breast cancer

Emmanuel Caruana ${ }^{1}$, Yohann Foucher ${ }^{1,2}$, Philippe Tessier ${ }^{1}$, Jean-Sébastien Frenel ${ }^{3}$, Jean-Marc Classe ${ }^{3}$, and Etienne Dantan ${ }^{1}$

1 INSERM UMR 1246 - SPHERE, Nantes University, Tours University, Nantes, France.

${ }^{2}$ Nantes University Hospital, Nantes, France.

${ }^{3}$ Institut de Cancérologie de I'Ouest, Centre René Gauducheau, Bd Jacques Monod 44800 Saint-Herblain, France.

Corresponding author: Etienne Dantan, INSERM UMR 1246 - SPHERE, Nantes University, Tours University, Nantes, France. IRS2, 22 boulevard Bénoni Goullin, 44200 Nantes, France. Phone: +33 2530091 23, Email: Etienne.Dantan@univnantes.fr 
Running head: Avoiding adjuvant CT in early breast cancer

Words count: 2670 


\section{Abstract}

Purpose. From the MINDACT trial, Cardoso et al. did not demonstrate a significant efficacy for adjuvant chemotherapy (CT) for women with early-stage breast cancer presenting high clinical and low genomic risks. Our objective was to assess the usefulness of the 70-gene signature in this population by using an alternative endpoint: the number of Quality-Adjusted Life-Years (QALYs), i.e. a synthetic measure of quantity and quality of life.

Methods. Based on the results of the MINDACT trial, we simulated a randomized clinical trial consisting of 1497 women with early-stage breast cancer presenting high clinical and low genomic risks. The individual preferences for the different health states and corresponding decrements were obtained from the literature.

Results. The gain in terms of 5-year disease free survival was $2.8 \%$ (95\% Cl from $0.1 \%$ to $5.7 \%$, from $90.4 \%$ for women without CT to $93.3 \%$ for women with CT). In contrast, due to the associated side effects, CT significantly reduced the number of QALYs by 62 days (95\% Cl from 55 to 70 days, from 4.13 years for women without CT to 3.96 years for women with CT).

Conclusion. Our results support the conclusions published by Cardoso et al. by providing additional evidence that the 70-gene signature can be used to avoid overtreatment by CT for women with high clinical risk but low genomic risk.

Keywords: 70-gene signature, breast cancer, patient-centered outcomes, stratified medicine, adjuvant chemotherapy 
Abbreviations: $95 \% \mathrm{Cl}$, 95\% Confidence Interval; ABC, Adjuvant Breast Cancer Trial; CMF, Cyclophosphamide, Methotrexate and Fluorouracil; CT, Chemotherapy; DFS, Disease-free Survival; DMFS, Distant Metastasis Free Survival; EBC, Early-stage Breast Cancer; E-CMF: Epirubicin followed by Cyclophosphamide, Methotrexate, Fluorouracil; EORTC, European Organisation for Research and Treatment of Cancer; FEC60, Fluorouracil, Epirubicin and Cyclophosphamide; FEC-D, FEC60 followed by docetaxel; Health-Related Quality of Life, HRQoL; HR, Hazard Ratio; MINDACT, Microarray In Node negative Disease may Avoid ChemoTherapy; NEAT, National Epirubicin Adjuvant Trial; QALYs, Quality-Adjusted Life-Years; TACT, Taxotere as Adjuvant Chemotherapy Trial. 


\section{Introduction}

In early-stage breast cancer (EBC), prognostic of long-term outcomes may help physicians and patients in the decision to utilize adjuvant treatments, for instance adjuvant chemotherapy (CT). This challenging issue led to the development of clinical prognostic scores such as Adjuvant! Online [1]. To improve such a clinical-based prognosis, the 70-gene signature (Mammaprint $\AA$ ) has been proposed [2-4], allowing the prediction of the risk of distant metastasis and death at 5 years $[5,6]$. The recent phase III randomized MINDACT trial (Microarray In Node negative Disease may Avoid ChemoTherapy) investigated the utility of the 70-gene signature in determining eligible patients for adjuvant CT [7]. Cardoso et al. notably concluded that CT for patients at high clinical risk but with low genomic risk led to a $1.5 \%$ higher 5 -year distant metastasis free survival (DMFS), defined as the time until the first distant metastatic recurrence or death from any cause. Considering the expected side effects of CT, this low efficacy suggested that women with high clinical risk but low genomic risk may not necessarily benefit from adjuvant CT [7].

Recently, Lange et al. reported that the conclusions of Cardoso et al. were questionable when considering disease-free survival (DFS) [8], defined as the time until the first disease progression (locoregional, distant relapse, ipsilateral or contralateral invasive breast cancer, ductal carcinoma in situ, or an invasive second primary cancer) or death from any cause, and thus remained questionable. In the high clinical risk and low genomic risk group, adjuvant CT was associated with a higher DFS, which was close to statistical significance $(\mathrm{HR}=0.71,95 \% \mathrm{Cl}$ from 0.50 to 1.01 , $\mathrm{p}=0.055$ ) [7]. The corresponding absolute difference in the DFS at 5 years was estimated at $2.8 \%$ (no $95 \% \mathrm{Cl}$ reported). Although this survival gain appears modest, 
this might be considered as a clinically relevant efficacy for adjuvant CT following the ASCO guidelines $[9,10]$.

The final decision regarding adjuvant CT always relies on the patient's choice after a clear information and discussion of the expected efficacy and the associated side effects. This was mentioned by Cardoso et al., but not formally considered in their analyses [7, 11]. Administering adjuvant CT may not necessarily be the best therapeutic option from the patient's perspective if a relatively small survival gain involves a significant deterioration of health-related quality of life (HRQoL) due to side effects. In a patient-centered perspective, the treatments should be compared against each other by weighting their consequences in terms of both survival and HRQoL [12, 13].

In this context, the main objective of our study was to complete the evaluation proposed by Cardoso et al. [7] of the usefulness of the 70-gene signature for deciding whether to administer adjuvant $\mathrm{CT}$ to women with $\mathrm{EBC}$ and classified as high clinical risk but low genomic risk. More precisely, we proposed a simulation-based study to estimate the impact of adjuvant CT in terms of Quality-Adjusted Life Years (QALYs), a patientcentered outcome especially appropriate for balancing quantity and quality of life. Although QALYs were primarily designed for the conduct of economic evaluations, their use in clinical research is increasingly encouraged [13-15].

\section{Materials and methods}

\section{Study population}

Data were extracted from the MINDACT trial [7]. A total of 6693 adult women with histologically confirmed primary invasive breast cancer (stage T1 or T2 or operable T3) were enrolled between 2007 and 2011. We restricted our analyses to the 1497 
women with high clinical risk but low genomic risk for whom 749 patients received adjuvant CT and 748 patients did not.

\section{Health utility values}

We defined the baseline age-specific utility value using the formula derived by Ara et al. for the UK general population [16]. Next, we used decrements in the utility related to different health states and treatment options in EBC as reported in the costeffectiveness study of Campbell et al. [17]. The authors estimated the patients' utility decrements corresponding to four treatment strategies: i) no chemotherapy, ii) chemotherapy using cyclophosphamide, methotrexate, and fluorouracil (CMF) as a first generation regimen, iii) chemotherapy using Epirubicin-CMF (E-CMF) or fluorouracil, epirubicin, and cyclophosphamide (FEC60) as a second generation regimen, iv) chemotherapy with FEC60 followed by docetaxel (FEC-D) as a third generation regimen. For this purpose, Campbell et al. used data from three randomized clinical trials: the Adjuvant Breast Cancer Trial $(A B C)$, the National Epirubicin Adjuvant Trial (NEAT) and the Taxotere as Adjuvant Chemotherapy Trial (TACT). The ABC and TACT trials used the Euroqol EQ-5D HRQol questionnaire for which patients' responses were converted into utility scores using the UK social tariffs [18]. For the NEAT trial, the authors had to convert answers to the EORTC QLQ-C30 and BR23 questionnaires into EQ-5D scores using regression analysis. Respecting the results of Campbell et al. [17], we assumed a decrease in utility of 0.003 for women having a mastectomy without adjuvant $\mathrm{CT}$. For patients receiving adjuvant $\mathrm{CT}$ after a surgery, we considered a more deteriorated HRQoL during the first 6 months, the average duration of the treatment. In the MINDACT trial, lymph node negative women with surgery and adjuvant CT received second generation anthracycline-based regimens or E-CMF for which we assumed a decrease in utility of 0.067 . Lymph node 
positive women received a third generation taxane-based regimen for which we assumed a decrease in utility of 0.099 . Beyond 6 months, women with third generation regimens had a decrease in utility of 0.035 versus 0.038 with second generation treatment. Additionally, Campbell et al. estimated the utility decrements given each subtype of disease progression (local recurrence, distant metastasis, secondary cancer) from a comprehensive review of the literature, using weighted averages of published utility values. Following Campbell et al., we thus assumed: a decrease of 0.108 due to local recurrence, 0.303 due to distant metastasis and 0.108 due to secondary cancer. The repartitions of these events were reported in Cardoso et al. From these data, we estimated the patients' expected health utility values given their age and CT regimen before and after the disease progression as detailed in Appendix 1 of the Web supplementary materials.

\section{Statistical analyses}

In our patient-centered approach, the principal outcome was the expected number of QALYs up to 5 years post-randomization. QALYs are a composite measure merging the length of life with corresponding HRQoL. The latter is captured by health utility values that represent the individuals' preferences over the various possible health states such that death is valued zero and perfect health equals one [19]. A higher health utility value corresponds to a preferred health state, i.e. a health state with a preferred HRQoL. More precisely, 1 QALY represents 1 year lived in an equivalent of perfect health. For instance, a patient living 10 years with a utility at 0.8 will have 8 QALYs (10*0.8). This value would be lower for a patient living for 12 years but with an utility value at 0.6 , the number of QALYs would then be $7.2\left(12^{\star} 0.6\right)$ due to a more efficient intervention but with important side effects. The secondary outcome was the DFS up to 5 years. 
The DFS curves were extracted from a digitalized picture of Figure 2C in Cardoso et al. [7] by using the R packages Readlmages and digitize [20]. Given the distribution of the patient age in Table 1 in the same paper, we assumed that the age was lognormal distributed with a $98 \%$ fluctuation interval in-between 35 and 70 years and truncated in-between 23 and 71 years. We also observed that the positive lymph-node status was Bernouilli distributed with a probability at $47.6 \%$.

Two thousand randomized clinical trials imitating the MINDACT trial were generated, the DFS being non-parametrically simulated as detailed in the Appendix 2 of the Web supplementary materials. The Kaplan-Meier estimator was used to obtain the DFS curves. The HR was obtained from the Cox model. For each randomized CT group, the number of expected QALYs was estimated by the area under the DFS up to 5 years weighted by the corresponding expected health utility values [15]. All statistical analyses were performed by using the 3.4.1 version of the $R$ software [21].

\section{Results}

\section{Disease-free survival}

As described in Table 1, women with adjuvant CT had a 5-year DFS equal to $93.3 \%$ (95\% Cl from $91.2 \%$ to $95.2 \%$ ) versus $90.4 \%$ (95\% Cl from $88.2 \%$ to $92.6 \%$ ) without adjuvant $\mathrm{CT}$, the absolute difference being equal to $2.8 \%$ (95\% $\mathrm{Cl}$ from $-0.1 \%$ to $5.7 \%$ ). The corresponding HR was $0.73(95 \% \mathrm{Cl}$ from 0.49 to 1.03). These results are concordant with Cardoso et al. [7]. Additionally, we estimated a mean time to the first disease progression or death up to 5 years at 4.87 years $(95 \% \mathrm{Cl}$ from 4.82 to 4.91 years) for women with adjuvant CT versus 4.80 years ( $95 \% \mathrm{Cl}$ from 4.74 to 4.85 years) for women without adjuvant CT. The related mean time gain due to adjuvant CT was 25 days (95\% $\mathrm{Cl}$ from 1 to 51 days). 


\section{Expected number of QALYs}

Merging the impacts of treatments on survival and HRQol, the expected number of QALYs was $3.96(95 \% \mathrm{Cl}$ from 3.95 to 3.97$)$ for women with adjuvant CT. In other words, the mean time in terms of equivalent years lived alive in perfect health was 3.96 years in this treatment group. In contrast, the expected number of QALYs was 4.13 (95\% Cl from 4.11 to 4.15$)$ for women without adjuvant CT. Therefore, the average survival gains in terms of equivalent years lived in perfect health appeared shorter for women receiving adjuvant CT: the loss was 62 days ( $95 \% \mathrm{Cl}$ from 55 to 70 days).

\section{Mean impact of treatments on the HRQoL}

From the previous results, we deduced the mean utility at $0.813(95 \% \mathrm{Cl}$ from 0.807 to 0.819 ) for women with adjuvant CT during the first 5 years post-treatment. In other words, it corresponds to an $18.7 \%$ decrease in perfect health. In comparison, the mean utility was $0.861(95 \% \mathrm{Cl}$ from 0.853 to 0.869$)$ for women without adjuvant $\mathrm{CT}$ during the first 5 years post-treatment, corresponding to a $13.9 \%$ decrease in perfect health. The absolute toxicity of adjuvant CT on the HRQoL corresponded to a decrement on mean utility of $0.047(95 \% \mathrm{Cl}$ from 0.038 to 0.058$)$.

\section{Discussion}

In the modern P4 medicine era [22], i.e. the predictive, preventive, personalized and participatory medicine, a patients understanding and consideration of the treatment consequences in terms of both efficacy and side effects should be of primary importance. Cardoso et al. [7] suggested avoiding adjuvant CT for women with EBC presenting high clinical but low genomic risks. They stated that the side effects on HRQoL induced by adjuvant CT would be more deleterious and would counterbalance the small survival gain. We formally validated their suggestion by using QALYs as the 
principal outcome in deciding the best therapeutic strategy in this high clinical risk but low genetic risk strata. We observed a significant decrease in the number of days alive in perfect health under adjuvant CT administration in this population (-62 days, $95 \% \mathrm{Cl}$ from -70 to -55 days).

The clinical use of genetic signatures in breast cancer is under discussion and recommendations has already been proposed [23]. Nevertheless, administrating adjuvant chemotherapy according to genomic signatures is still an open question. For instance, Sparano et al. recently assessed the benefit of adjuvant therapy for women with hormone-receptor positive, HER2-negative, and axillary node-negative breast cancer and presented an intermediate genetic risk of recurrence on a 21-gene signature [24]. They observed a significant interaction between age and adjuvant chemotherapy leading to a benefit for women younger than 50 years for a specific strata of the 21-gene risk signature. However, as in the MINDACT study [7], the judgment criteria were only defined in terms of quantity of life without consideration for quality of life. By contrast, the patient-centered approach we propose allows assessing the benefit/risk balance of adjuvant chemotherapy using a composite criterion combining the quantity and the quality of life. In our opinion, future clinical trials should be more frequently designed using QALYs as the primary endpoint and analyzed from such type of patient-centered perspective. Some studies in oncology already endorsed this point of view $[25,26]$. Besides, recent methodological researches explored the calibration conditions in terms of survival and utilities differences for clinical studies that would be designed to assess differences in terms of QALYs [14] and have demonstrated that this may improve statistical power and reduce the required sample size under certain specific conditions [27]. Nevertheless, most cancer studies still use survival as the main judgement criteria while HRQoL is not systematically considered 
even if recommendations exist [13]. When both survival and HRQoL outcomes are considered, they are most of the times examined separately. This separation may be due to the statistical difficulties related to the simultaneous analysis of the two processes. To assess the clinical utility of a treatment/intervention, the statistical analysis should consider the survival times weighted by the utility scores instead of the observed survival times [28, 29]. This requires the collection of individual utilities all along the study follow-up whether obtained by converting cancer-specific health-states utility questionnaires such as the EORTC QLQ-C30 [30] or by using generic preference-based questionnaires such as the Euroqol EQ-5D [31].

Initially developed for cost-utility analysis that seeks to inform resources allocation in health care, QALYs may also offer promising perspectives for patient-centered decision making. Kind et al. argued that considering QALYs in the taking care process would change the patient's regard about medical decision although it would require an important educational prerequisite to understand the concept of QALYs [32]. We think that using QALYs as a primary endpoint may participate to a paradigm shift from clinical efficacy (raw survival gain) to clinical utility (survival weighted by patient consideration for the health states). Indeed, thinking in terms of QALYs forces to explicitly consider the trade-off between the quantity and the quality of life. As such, QALYs may be a useful tool to better inform the patient about the possible complex consequences of treatment and thus to facilitate shared medical decision. For instance, in our context, it may be relevant to explain to patients with $\mathrm{EBC}$ why adjuvant chemotherapy would not be proposed to women presenting high clinical and low genomic risks since it seemed associated with a decrease in QALYs, i.e. a decrease of the expected life time lived in perfect health of about 2 months. 
Nevertheless, several limitations have to be underlined. Firstly, our study was mainly based on one single previously published clinical trial [7]. This obviously needs to be analyzed using additional independent studies on the utility of the 70-gene signature in administrating adjuvant CT. Nevertheless, we conducted a systematic review as detailed in Appendix 3 of the Web supplementary materials, leading to retain no additional study. Secondly, implementing our approach based on the expected number of QALYs requires making assumptions about the potential consequences of stratified medicine. Here, we used published decrements in utility scores for CT regimens used in United Kingdom [33-35]. It could be argued that this may be unrepresentative of the MINDACT regimen used. Additionally, we did not consider uncertainty surrounding individual utilities. It could be preferable to directly measure the preferences of patients for the various health states in order (i) to take into consideration their variability when calculating the expected number of QALYs, and (ii) to avoid assumptions when using published utility values. Thirdly, we used a 5-years time horizon to estimate the number of QALYs. This allowed us to assess the trade-off between quantity and quality of life during the first 5 years, while adjuvant CT may have possible long-term consequences on $\mathrm{HRQoL}$. For both groups, the change in long-term HRQoL might be underestimated due to this limitation and it appears essential to further assess the long-term impact by updating the results in several years.

In conclusion, despite the inherent limitation of such a simulation-based study, our results formally confirm the suggestion of Cardoso et al. taking into account both survival and HRQol as important outcomes [7]. We recommend the use of the 70-gene signature in high clinical risk women to avoid overtreatment by adjuvant CT when their genomic risk is low. 


\section{Acknowledgements and Funding Information}

This work was supported by the Cancer National Institute (INCa, MAP-MARKER, N²013-137).

\section{Compliance with Ethical standards}

\section{Disclosure of potential conflicts of interest}

The authors declare that they have no conflict of interest.

Research involving human participants and/or animals

This article does not contain any studies with animals performed by any of the authors. Informed consent

For this type of study formal consent is not required 


\section{References}

1. Ravdin PM, Siminoff LA, Davis GJ, et al (2001) Computer program to assist in making decisions about adjuvant therapy for women with early breast cancer. $\mathrm{J}$ Clin Oncol 19:980-991. https://doi.org/10.1200/JCO.2001.19.4.980

2. Buyse M, Loi S, van't Veer L, et al (2006) Validation and Clinical Utility of a 70Gene Prognostic Signature for Women With Node-Negative Breast Cancer. J Natl Cancer Inst 98:1183-1192. https://doi.org/10.1093/jnci/djj329

3. Bueno-de-Mesquita JM, Linn SC, Keijzer R, et al (2009) Validation of 70-gene prognosis signature in node-negative breast cancer. Breast Cancer Res Treat 117:483-495. https://doi.org/10.1007/s10549-008-0191-2

4. Mook S, Schmidt MK, Viale G, et al (2009) The 70-gene prognosis-signature predicts disease outcome in breast cancer patients with 1-3 positive lymph nodes in an independent validation study. Breast Cancer Res Treat 116:295-302. https://doi.org/10.1007/s10549-008-0130-2

5. van 't Veer LJ, Dai H, van de Vijver MJ, et al (2002) Gene expression profiling predicts clinical outcome of breast cancer. Nature 415:530-536. https://doi.org/10.1038/415530a

6. Harris L, Fritsche H, Mennel R, et al (2007) American Society of Clinical Oncology 2007 update of recommendations for the use of tumor markers in breast cancer. $\mathrm{J}$ Clin Oncol 25:5287-5312. https://doi.org/10.1200/JCO.2007.14.2364

7. Cardoso F, van't Veer LJ, Bogaerts J, et al (2016) 70-Gene Signature as an Aid to Treatment Decisions in Early-Stage Breast Cancer. New England Journal of Medicine 375:717-729. https://doi.org/10.1056/NEJMoa1602253

8. Lange S, Scheibler F, Fleer D, Windeler J (2017) Interpretation of the Results of the MINDACT Study and Consequent Recommendations in the Updated ASCO Clinical Practice Guideline. JCO 36:429-430. https://doi.org/10.1200/JCO.2017.75.9506

9. Harris LN, Ismaila N, McShane LM, et al (2016) Use of Biomarkers to Guide Decisions on Adjuvant Systemic Therapy for Women With Early-Stage Invasive Breast Cancer: American Society of Clinical Oncology Clinical Practice Guideline. J Clin Oncol 34:1134-1150. https://doi.org/10.1200/JCO.2015.65.2289

10. Krop I, Ismaila N, Andre F, et al (2017) Use of Biomarkers to Guide Decisions on Adjuvant Systemic Therapy for Women With Early-Stage Invasive Breast Cancer: American Society of Clinical Oncology Clinical Practice Guideline Focused Update. J Clin Oncol 35:2838-2847. https://doi.org/10.1200/JCO.2017.74.0472

11. Thewes B, Prins J, Friedlander M (2016) 70-Gene Signature in Early-Stage Breast Cancer. N Engl J Med 375:2199-2200. https://doi.org/10.1056/NEJMc1612048

12. Basch E (2013) Toward patient-centered drug development in oncology. N Engl J Med 369:397-400. https://doi.org/10.1056/NEJMp1114649 
13. Foucher $\mathrm{Y}$, Lorent $\mathrm{M}$, Tessier $\mathrm{P}$, et al (2018) A mini-review of quality of life as an outcome in prostate cancer trials: patient-centered approaches are needed to propose appropriate treatments on behalf of patients. Health Qual Life Outcomes 16:40. https://doi.org/10.1186/s12955-018-0870-6

14. Sloan JA, Sargent DJ, Novotny PJ, et al (2014) Calibration of quality-adjusted life years for oncology clinical trials. J Pain Symptom Manage 47:1091-1099.e3. https://doi.org/10.1016/j.jpainsymman.2013.07.016

15. Dantan E, Foucher $Y$, Lorent M, et al (2016) Optimal threshold estimator of a prognostic marker by maximizing a time-dependent expected utility function for a patient-centered stratified medicine. Statistical Methods in Medical Research 096228021667116. https://doi.org/10.1177/0962280216671161

16. Health related quality of life by age, gender and history of cardiovascular disease: results from the Health Survey for England - HEDS_DP_09-12.pdf. http://eprints.whiterose.ac.uk/10880/1/HEDS_DP_09-12.pdf. Accessed 20 Nov 2017

17. Campbell HE, Epstein D, Bloomfield D, et al (2011) The cost-effectiveness of adjuvant chemotherapy for early breast cancer: A comparison of no chemotherapy and first, second, and third generation regimens for patients with differing prognoses. European Journal of Cancer 47:2517-2530. https://doi.org/10.1016/j.ejca.2011.06.019

18. Dolan P, Gudex C, Kind P, Williams A (1995) A social tariff for EuroQol: results from a UK general population survey. Centre for Health Economics, University of York

19. Weinstein MC, Torrance G, McGuire A (2009) QALYs: the basics. Value Health 12 Suppl 1:S5-9. https://doi.org/10.1111/j.1524-4733.2009.00515.x

20. Poisot $\mathrm{T}$ (2011) The digitize package: extracting numerical data from scatterplots. The R Journal 3:25-26

21. R Development Core Team . (2010) R: A Language and Environment for Statistical Computing. Vienna, Austria

22. Flores M, Glusman G, Brogaard K, et al (2013) P4 medicine: how systems medicine will transform the healthcare sector and society. Per Med 10:565-576. https://doi.org/10.2217/PME.13.57

23. Duffy MJ, Harbeck N, Nap M, et al (2017) Clinical use of biomarkers in breast cancer: Updated guidelines from the European Group on Tumor Markers (EGTM). Eur J Cancer 75:284-298. https://doi.org/10.1016/j.ejca.2017.01.017

24. Sparano JA, Gray RJ, Makower DF, et al (2018) Adjuvant Chemotherapy Guided by a 21-Gene Expression Assay in Breast Cancer. New England Journal of Medicine 379:111-121. https://doi.org/10.1056/NEJMoa1804710 
25. Collinson FJ, Gregory WM, McCabe C, et al (2012) The STAR trial protocol: a randomised multi-stage phase II/III study of Sunitinib comparing temporary cessation with allowing continuation, at the time of maximal radiological response, in the first-line treatment of locally advanced/metastatic Renal Cancer. BMC Cancer 12:. https://doi.org/10.1186/1471-2407-12-598

26. Royce TJ, Feldman AS, Mossanen M, et al (2018) Comparative Effectiveness of Bladder-preserving Tri-modality Therapy Versus Radical Cystectomy for Muscleinvasive Bladder Cancer. Clin Genitourin Cancer. https://doi.org/10.1016/j.clgc.2018.09.023

27. Ferguson ND, Scales DC, Pinto R, et al (2013) Integrating Mortality and Morbidity Outcomes. Am J Respir Crit Care Med 187:256-261. https://doi.org/10.1164/rccm.201206-1057OC

28. Glasziou PP, Simes RJ, Gelber RD (1990) Quality adjusted survival analysis. Statistics in Medicine 9:1259-1276. https://doi.org/10.1002/sim.4780091106

29. Cole BF, Gelber RD, Goldhirsch A (1993) Cox regression models for quality adjusted survival analysis. Stat Med 12:975-987

30. Aaronson NK, Ahmedzai S, Bergman B, et al (1993) The European Organization for Research and Treatment of Cancer QLQ-C30: A Quality-of-Life Instrument for Use in International Clinical Trials in Oncology. J Natl Cancer Inst 85:365-376. https://doi.org/10.1093/jnci/85.5.365

31. Towse A (2010) Net clinical benefit: the art and science of jointly estimating benefits and risks of medical treatment. Value Health 13 Suppl 1:S30-32. https://doi.org/10.1111/j.1524-4733.2010.00753.x

32. Kind P, Lafata JE, Matuszewski K, Raisch D (2009) The use of QALYs in clinical and patient decision-making: issues and prospects. Value Health 12 Suppl 1:S2730. https://doi.org/10.1111/j.1524-4733.2009.00519.x

33. Ellis $P$, Barrett-Lee $P$, Johnson $L$, et al (2009) Sequential docetaxel as adjuvant chemotherapy for early breast cancer (TACT): an open-label, phase III, randomised controlled trial. Lancet 373:1681-1692. https://doi.org/10.1016/S0140-6736(09)60740-6

34. Poole CJ, Earl HM, Hiller L, et al (2006) Epirubicin and Cyclophosphamide, Methotrexate, and Fluorouracil as Adjuvant Therapy for Early Breast Cancer. New England Journal of Medicine 355:1851-1862. https://doi.org/10.1056/NEJMoa052084

35. Adjuvant Breast Cancer Trials Collaborative Group (2007) Polychemotherapy for early breast cancer: results from the international adjuvant breast cancer chemotherapy randomized trial. J Natl Cancer Inst 99:506-515. https://doi.org/10.1093/jnci/djk108 
Table 1. Complementarity of the results from the study proposed by Cardoso et al. [7] and from our simulations.

\begin{tabular}{|c|c|c|c|c|c|c|}
\hline & \multicolumn{3}{|c|}{ Results from the simulations } & \multicolumn{3}{|c|}{ Results in Cardoso et al. [7] } \\
\hline & $\begin{array}{c}\text { No } \\
\text { chemotherapy }\end{array}$ & $\begin{array}{c}\text { With } \\
\text { chemotherapy }\end{array}$ & $\begin{array}{c}\text { Absolute } \\
\text { difference }\end{array}$ & $\begin{array}{c}\text { No } \\
\text { chemotherapy }\end{array}$ & $\begin{array}{c}\text { With } \\
\text { chemotherapy }\end{array}$ & $\begin{array}{l}\text { Absolute } \\
\text { difference }\end{array}$ \\
\hline $\begin{array}{l}\text { DFS probability at } 5 \text { years } \\
\qquad(95 \% \mathrm{Cl})\end{array}$ & $\begin{array}{c}90.4 \% \\
(88.2,92.6)\end{array}$ & $\begin{array}{c}93.3 \% \\
(91.2,95.2)\end{array}$ & $\begin{array}{c}2.8 \% \\
(-0.1,5.7)\end{array}$ & $\begin{array}{c}90.1 \% \\
(87.5,92.1)\end{array}$ & $\begin{array}{c}92.9 \% \\
(90.5,94.7)\end{array}$ & $\begin{array}{c}2.8 \% \\
\text { (no } 95 \% \mathrm{Cl} \\
\text { reported) }\end{array}$ \\
\hline $\begin{array}{c}\text { Hazard Ratio } \\
(95 \% \mathrm{Cl})[\mathrm{p} \text {-value] }\end{array}$ & & $\begin{array}{c}0.73^{a} \\
(0.49,1.03) \\
\end{array}$ & & & $\begin{array}{c}0.71^{a} \\
(0.50,1.01)[p=0.055]\end{array}$ & \\
\hline $\begin{array}{l}\text { Mean time to disease } \\
\text { progression or death up } \\
\text { to } 5 \text { years }(95 \% \mathrm{Cl})\end{array}$ & $\begin{array}{l}4.80 \text { years } \\
(4.74,4.85)\end{array}$ & $\begin{array}{l}4.87 \text { years } \\
(4.82,4.91)\end{array}$ & $\begin{array}{c}+25 \text { days } \\
(1,51)\end{array}$ & - & - & - \\
\hline $\begin{array}{c}\text { QALYs up to } 5 \text { years } \\
(95 \% \mathrm{Cl})\end{array}$ & $\begin{array}{c}4.13 \text { years } \\
(4.11,4.15)\end{array}$ & $\begin{array}{c}3.96 \text { years } \\
(3.95,3.97)\end{array}$ & $\begin{array}{l}-62 \text { days } \\
(-70,-55)\end{array}$ & - & - & - \\
\hline $\begin{array}{c}\text { Mean utility within the } 5 \\
\text { first years } \\
(95 \% \mathrm{CI})\end{array}$ & $\begin{array}{c}0.861 \\
(0.853,0.869)\end{array}$ & $\begin{array}{c}0.813 \\
(0.807,0.819)\end{array}$ & $\begin{array}{c}-0.047 \\
(-0.058,-0.038)\end{array}$ & - & - & - \\
\hline
\end{tabular}

a No chemotherapy being the reference group 